\title{
SYNANTROPIJNE STANOWISKO ERYSIMUM WITTMANNII ZAW. (BRASSICACEAE) W BESKIDZIE SĄDECKIM
}

\author{
A SYNANTHROPIC POPULATION OF A CARPATHIAN ENDEMIC SPECIES, \\ ERYSIMUM WITTMANNII ZAW. (BRASSICACEAE), IN THE BESKID SĄDECKI MTS.
}

\author{
Aneta CZarna
}

A. Czarna, Katedra Botaniki, Uniwersytet Przyrodniczy w Poznaniu, Wojska Polskiego 71 C, 60-625 Poznań, Poland, e-mail: aneta.czarna@up.poznan.pl, (10 https://orcid.org/0000-0002-8687-7019

\begin{abstract}
A new local population of a Carpathian endemic plant species, Erysimum wittmannii, was found in Szczawnica in concrete-filled crevices between large stones on a steep slope falling to the Dunajec River, slightly downstream from the stream Grajcarek, when walking from Krościenko. This is certainly its largest, although anthropogenic, local population in the Polish Carpathians. On 14 July 2020, it included 45 fruiting individuals and two flowering ones.
\end{abstract}

KeY WORDS: Erysimum wittmannii, mountain species, endemic species, Beskid Sądecki Mts.

Erysimum wittmannii Zaw. (pszonak Wittmanna) jest endemitem karpackim, który w Polsce występuje wyłącznie w Pieninach (LATowski 1985). Rośnie na skałach i usypiskach wapiennych (SzAFER i in. 1986), zarówno w miejscach nasłonecznionych, jak i zacienionych $\mathrm{w}$ reglu dolnym $\mathrm{w}$ całym paśmie Pienin (SzELĄG 2008). Otrzymał kategorię zagrożenia LC według
IUCN z 2001 roku, czyli gatunek niższego ryzyka (SZELĄG 2008).

Nowe stanowisko znajduje się w Beskidzie Sądeckim, należącym do Beskidu Zachodniego (ryc. 1). Położone jest w miejscowości Szczawnica, powiat nowotarski, tuż przed potokiem Grajcarek od strony Krościenka (ryc. 2a). Erysimum wittmannii rośnie na

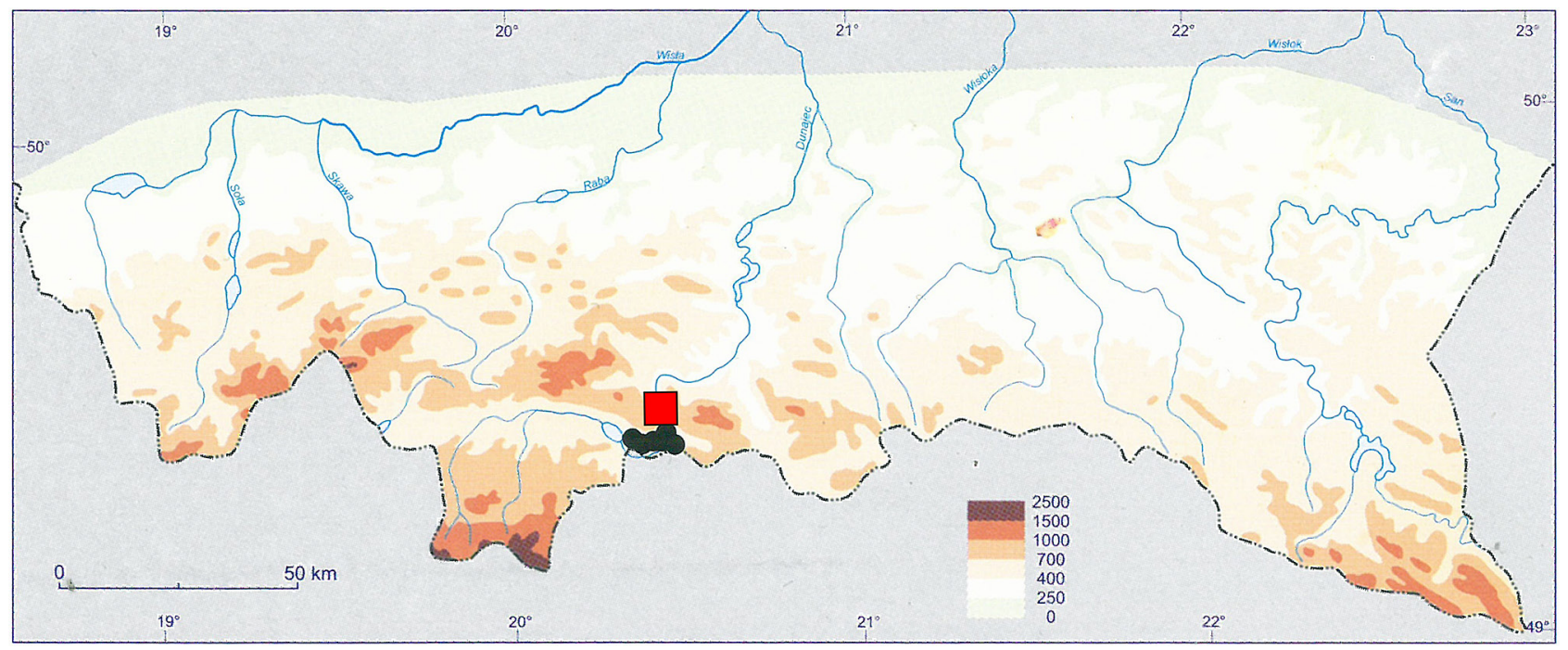

Ryc. 1. Rozmieszczenie pszonaka Wittmanna Erysimum wittmannii w Polsce (według Szeląg 2008, uzupełnione); czerwony kwadrat - nowe stanowisko

Fig. 1. Distribution of Erysimum wittmannii in Poland (according to SzELĄG 2008, modified); red square - new locality 
wysokim stoku opadającym do rzeki Dunajec, w betonowanych szczelinach między dużymi kamieniami (ryc. 2c, d). Jest to zapewne najliczniejsze stanowisko $\mathrm{w}$ polskich Karpatach, ma jednak charakter synantropijny. Charakteryzowane stanowisko zajmuje powierzchnię około $350 \mathrm{~m}^{2}$. W roku odkrycia, a dokładnie 26.07.2009, występowało tu 66 osobników pszonaka Wittmanna, a 14.07.2020 roku stwierdzono 45 osobników owocujących i dwa jeszcze kwitnące (ryc. 2b). Na tym stanowisku rośliny zawiązywały bardzo licznie nasiona, które wykorzystano i scharakteryzowano w pracy CZARNej i in. (2016). Wśród innych górskich roślin towarzyszących tytułowemu gatunkowi wystąpił jeden okaz Alyssum saxatile (smagliczka skalna).

Skład florystyczny płatu z udziałem Erysimum wittmannii przedstawia poniższe zdjęcie fitosocjologiczne. Zdj. 1. Szczawnica, powiat nowotarski, województwo małopolskie. Koordynaty: $49.25477^{\circ} \mathrm{N}$, 20.27546 ${ }^{\circ}$ E. Data wykonania zdjęcia: 14.07.2020, powierzchnia - $350 \mathrm{~m}^{2}$, liczba gatunków - 31 .
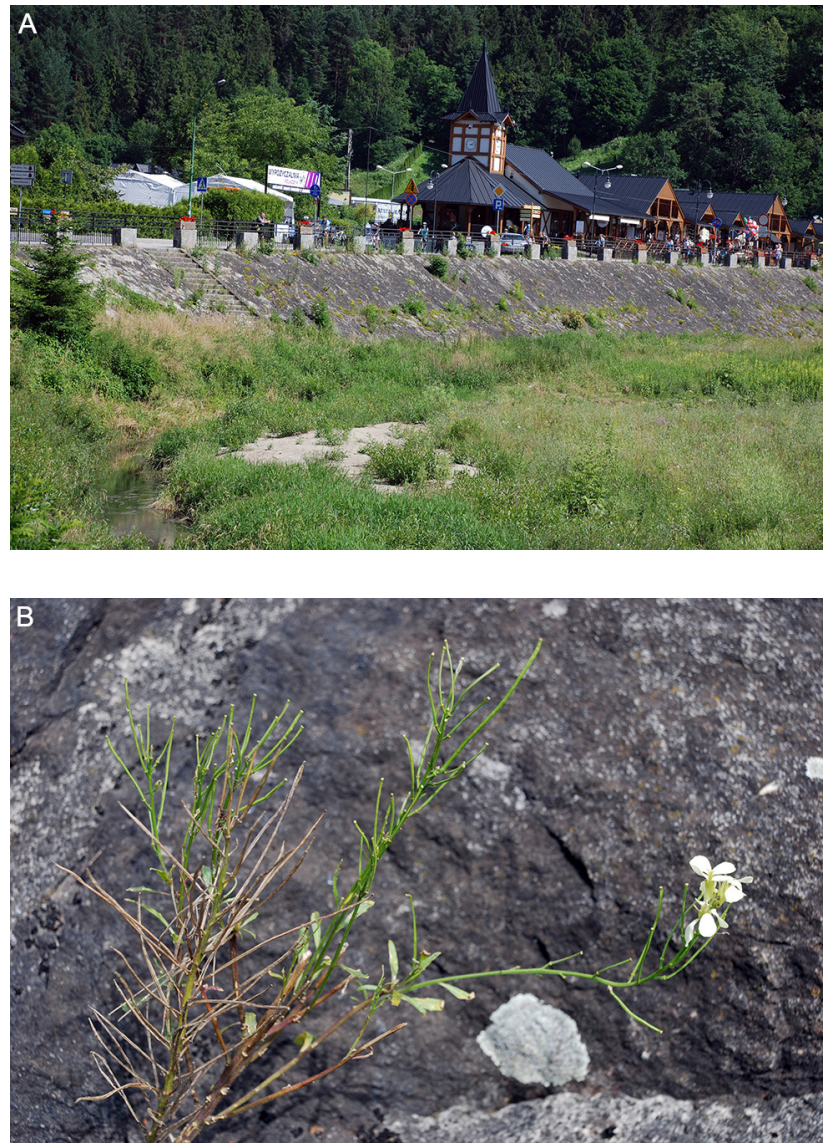

Ryc. 2. Erysimum wittmannii nad Dunajcem w Szczawnicy: A - widok na populację, B - kwitnący osobnik, C - w towarzystwie innych roślin, D - samodzielnie w betonowych szczelinach między dużymi kamieniami (14.07.2020, fot. A. Czarna)

Fig. 2. Erysimum wittmannii on the Dunajec River in Szczawnica: A - local population, B - flowering individual, C accompanied by other plants, $\mathrm{D}$ - solitary individual in concrete-filled crevices (14.07.2020, photo: A. Czarna)
Pokrycie warstwy A - 0\%, B - 0\%, C-80\% (same szczeliny między kamieniami). C: Partenocissus quinquefolia 2, Erysimum wittmannii 1, Poa compressa 1, Salvia verticillata 1, Sedum sexangulare 1, Artemisia vulgaris + , Clinopodium vulagare + , Crepis biennis, +, Euphorbia cyparissias + , Fraxinus excelsior + , Galium mollugo + , Lactuca serriola + , Origanum vulgare + , Plantago lanceolata + , Rosa canina + , Senecio viscosus + , Achillea millefolium r, Agrimonia eupatoria r, Alyssum saxatile r, Barbarea vulgaris r, Cirsium vulgare r, Conyza canadensis r, Daucus carota r, Elymus repens $\mathrm{r}$, Impatiens parviflora $\mathrm{r}$, Lapsana communis $\mathrm{r}$,
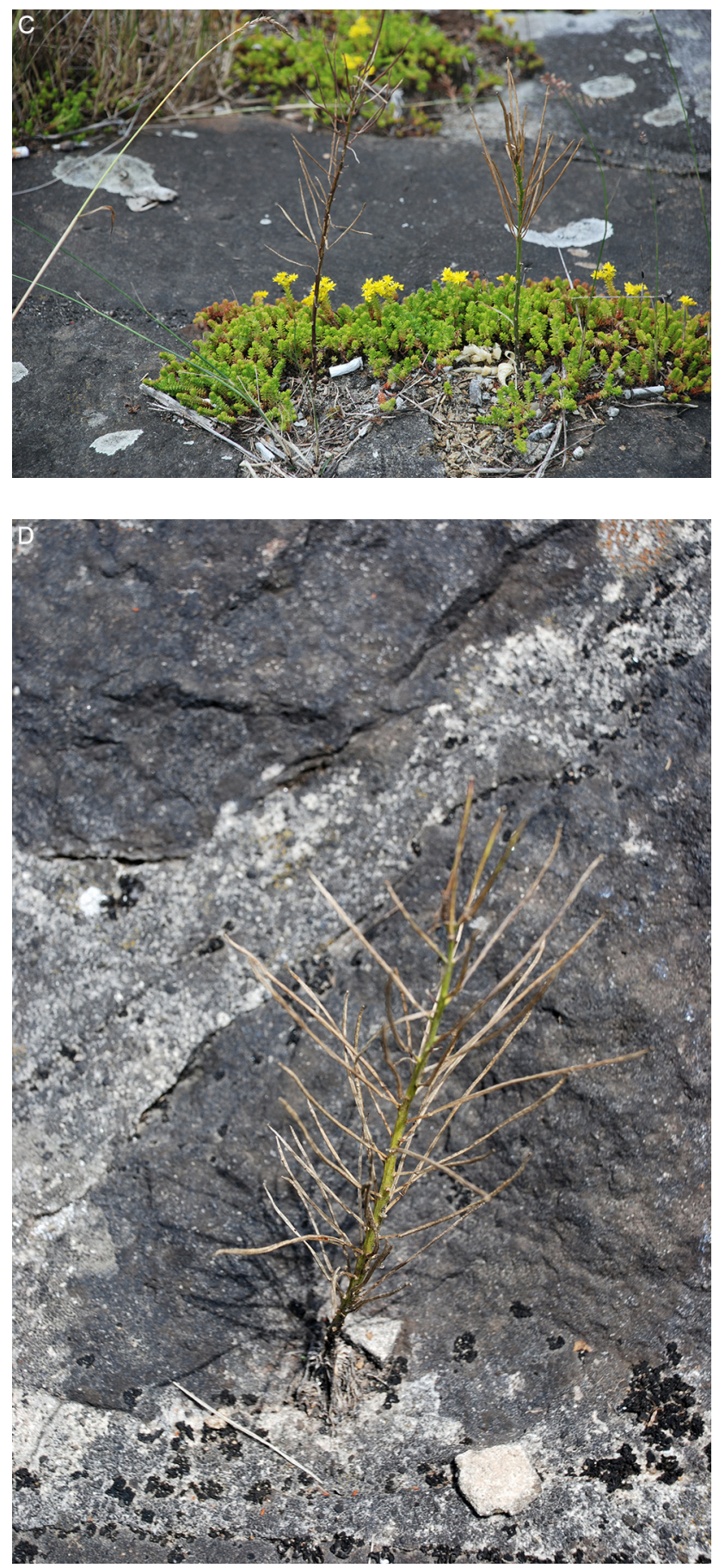
Medicago lupulina r, Oenothera rubricaulis r, Sedum spurium $\mathrm{r}$, Sonchus oleraceus $\mathrm{r}$, Trifolium pratense $\mathrm{r}$. Głównym zagrożeniem dla stanowiska Erysimum wittmannii może być utrzymujący się szczególnie długo wysoki poziom rzeki Dunajec, a także rozrastający się winobluszcz pięciolistkowy (Parthenocissus quinquefolia). W 2020 roku obserwowano ćwiczącego wspinacza na stoku z omawianym stanowiskiem. Mimo $\dot{z}$ jest to stanowisko antropogeniczne, wymaga obserwacji i zachowania ze względu na endemiczny charakter Erysimum wittmannii.

\section{LITERATURA}

Czarna A., Gawrońska B., Nowińska R., MorozowsKA M., KosińsKi P. (2016): Morphological and mo- lecular variation in selected species of Erysimum (Brassicaceae) from Central Europe and their taxonomic significance. Flora 222: 68-85.

LAtowski K. (1985): Erysimum L. W: A. Jasiewicz (red.). Flora Polski. Rośliny naczyniowe. T. 4. Państwowe Wydawnictwo Naukowe, WarszawaKraków: 149-156.

SzAFer W., KulczyŃski S., Pawłowski B. (1986): Rośliny polskie. Państwowe Wydawnictwo Naukowe, Warszawa.

SzelĄG Z. (2008): Pszonak Wittmanna, Erysimum wittmannii Zaw. W: Z. Mirek, H. Piękoś-Mirkowa (red.). Czerwona księga Karpat Polskich. Rośliny naczyniowe. Instytut Botaniki im. W. Szafera PAN, Instytut Ochrony Przyrody PAN, Kraków: 152-153. 